\title{
Significance of Road Infrastructure on Economic Sustainability
}

\author{
Sidiq Okwudili Ben \\ Department of Geography, College of Education Ikere, Ekiti, Nigeria
}

\begin{abstract}
This study buttressed on the theories explaining the significance of road infrastructure on economic sustainability. Road infrastructure is essential for banishing hunger, alleviating poverty, and improving the quality of human life. Road transport is a means of transport that offers door-to-door transport which is suitable for the delivery of finished goods to consumers. Road infrastructure has the potentials of transforming subsistence farming into a commercial and dynamic farming system which unlock the potentials embedded in rural areas. Understanding the conditions in which more or new road infrastructure does indeed foster economic growth is crucial for efficient management of road infrastructural project. Neoclassical growth theory, endogenous growth theory, growth pole, and growth centre theory were discussed. This paper concludes that public investment should not be constrained by accounting methods that impede a focus on economic returns, and road pricing strategy should be adopted in Nigeria because of its benefits of spreading demand for road transport, minimizing congestion and overcrowding, improving reliability and delivering benefits to the wider economy.
\end{abstract}

Keywords: road, infrastructure, economy, sustainability

DOI: $10.7176 / \mathrm{JAAS} / 66-01$

Publication date:July $31^{\text {st }} 2020$

\section{Introduction}

Transport was derived from two Latin words "trans" which mean across and "portare" which mean carry (Adeniran, 2016). It is an act, process, or instance of moving people and goods through a means of conveyance from one location to another. It is also a system for carrying passengers, raw materials and goods from one place to another often through power driven machines. Transportation modes are an essential component of transport systems since they are the means by which mobility is supported. Mobility is often understood as short-term decisions of travel choices (Papacostas and Prevedouros, 2000) such as frequency of travel for various purposes, mode, and destination, routes, cost and time of trips.

Mobility should also be viewed as being related to long-term decisions such as shelter and job types of locations, vehicle ownership and its usage for accessing the city. Mobility or accessing the city is crucial for everyone in the city. It is more crucial for poor people as it is linked with the possibilities of escaping poverty and deprivation. Geographers consider a wide range of modes that may be grouped into three broad categories based on the medium they exploit: land, water and air. Each mode has its own requirements and features, and is adapted to serve the specific demands of freight and passenger traffic. This study focused on road transport mode (Rodrigue, Claude, and Brian, 2006).

In the same vein, road transport has become the dominant land transport system today. Automobiles, buses and trucks require a road bed. Such infrastructures are moderately expensive to provide, but there is a wide divergence of costs, from a gravel road to a multi-lane urban expressway. Because vehicles have the means to climb moderate slopes, physical obstacles are less important than for some other land modes. Most roads are provided as a public good by governments, while the vast majority of vehicles are owned privately. The capital costs, therefore, are shared, and do not fall as heavily on one source as is the case for other modes. All road transport modes have limited abilities to achieve scale economies. This is due to the size constraints imposed by governments and also by the technical and economic limits of the power sources.

The importance of infrastructure in the development of any society cannot be overemphasized, this connotes the axiom of Dr. Rao who states that "the link between infrastructure and economic development is not a once and for all affair. It is a continuous process; and progress in development has to be preceded, accompanied, and followed by progress in infrastructure, if we are to fulfil our declared objectives of generating a self accelerating process of economic development."

It is important to note that the need for greater road infrastructure investment is clear; equally important is the need to sustainably manage such investments. The Nigerian Government's success in road infrastructure provision will be measured not by the quantum of funds invested, but on how road infrastructure contributes to the achievement of Nigeria's economic, social and environmental objectives. Importantly, road infrastructure investment should be considered as a means to an end, not an end in itself; this is in line with transport as it has been established by transport economists that it is a means to an end, and not an end itself, hence it is said to be a derived demand.Road infrastructure is a form of transport infrastructure; hence, it is a means to an end.

As many forms of infrastructure can take, as diverse are its potential effects on economic growth. Even for the same type of infrastructure e.g., a road, the economic effect may be very different depending on the setting. A 
new road infrastructure fully equipped with road fittings and installations may be very beneficial if it is located where it will be highly economical most especially when constructed in industrial and commercial areas, or if it removes a bottleneck, or it may be of little economic value in case it constitutes an unnecessary capacity expansion. As a result, more infrastructures may not necessarily help, while a lack of adequate infrastructure may constitute a barrier to economic growth. Understanding under which conditions more or a new infrastructure does indeed foster economic growth is therefore an important issue.

Barro (1990) is of the view from a theoretical point that one of the main questions concerning the relationship between infrastructure and economic growth is whether infrastructure raises growth in a transitory way, as the inclusion of infrastructure in a neoclassical growth model would predict, or whether it spurs growth on a permanent basis in the spirit of the endogenous growth theory. Again, this may depend on the specific circumstances and differ across infrastructure types transportation may primarily bring transitory benefits.

Challenges in infrastructure provision are not unique to a particular country. Uncertainty and scarcity of available funds for road infrastructural investment, and competing priorities present challenges togovernments infrastructure planning and delivery. Sustainability requires that future generations are not compromised by the investment decisions of current generations. Managing the road infrastructure through appropriate pricing, funding and prioritisation frameworks is crucial to accrue benefits in developing key social and economic structure of the country.

From empirical point of view, the analysis of the effect of road infrastructure on economic growth is characterized by a number of difficulties. Above all, establishing causality between the road infrastructure in place and economic growth emerges as the major challenge. Investments in road infrastructure may foster economic growth. At the same time, however, growth can also create demand for additional or new types of road infrastructure and render existing infrastructures and installations obsolete. Due to this two-way interdependency between infrastructure provision and economic growth, econometric analyses of infrastructure investments may be subject to endogeneity biases. This study stressed on how to sustain road infrastructure projects in Nigeria.

\section{Conceptual Framework}

\subsection{Transport system}

According to Adeniran (2016), transport industry is a system that ensures successful movement of passengers, cargoes and mails from one point to another point through various modes such as air, water, road, rail, pipeline, and cable. The industry is not a homogenous body of its own but it is made up of different interacting sub-system working interrelated to ensure the performance of its objectives. Each mode has its various sub-systems or components. The sub-systems are;

1. The way: This is the route where vehicle plies. It can be natural (for water way and air way) or artificial (for paved road ways, railway, and cable);

2. The vehicle: This is the carrying capacity for different transport modes such as motor car for road, aircraft for air, ship for water, pipe or tube for pipeline and each has different sizes and classes;

3. The terminal: This is a point where there is an access to specialized way. It is used for interchange, fragmentation and consolidation of traffic for onward movement. Examples are bus-stop, airport, seaport, depot, railway and station); and

4. The motive power: This is the propeller that moves the entire vehicle e.g. the engine, tires, fuel and others.

For an effective road transport system, it must comprise the road way which includes infrastructures and fittings, the motor vehicle which is the carrying capacity on the road, the bus terminal, and the motive power for vehicle. Apart from the road infrastructure, there is need for management of road transport operations.

\subsection{Effects of road transport investment on economic development}

Road transport investment here mainly refers to the road infrastructure investment. The construction and operation of road infrastructure has an important impact on economic development. Many economists have been engaged in this field, and have pointed out that there are two types of effects of road transport infrastructure on economic development:

1. Forward-induced effects of road construction on economic growth and

2. Road construction follow-up ripple effects on economic growth.

\subsubsection{Forward-induced effects of road construction on economic growth}

The effect of economic activity affecting economic output of forward-induced effects is seen in building road transport infrastructure to boosts economic development. Road construction projects affect economic development. Road transport infrastructure must produce demand of factors of production, thereby increasing the investment of factor markets, and prosperity factor market will stimulate the consumer market investment, so construction of road transport infrastructure will stimulate much investment. 


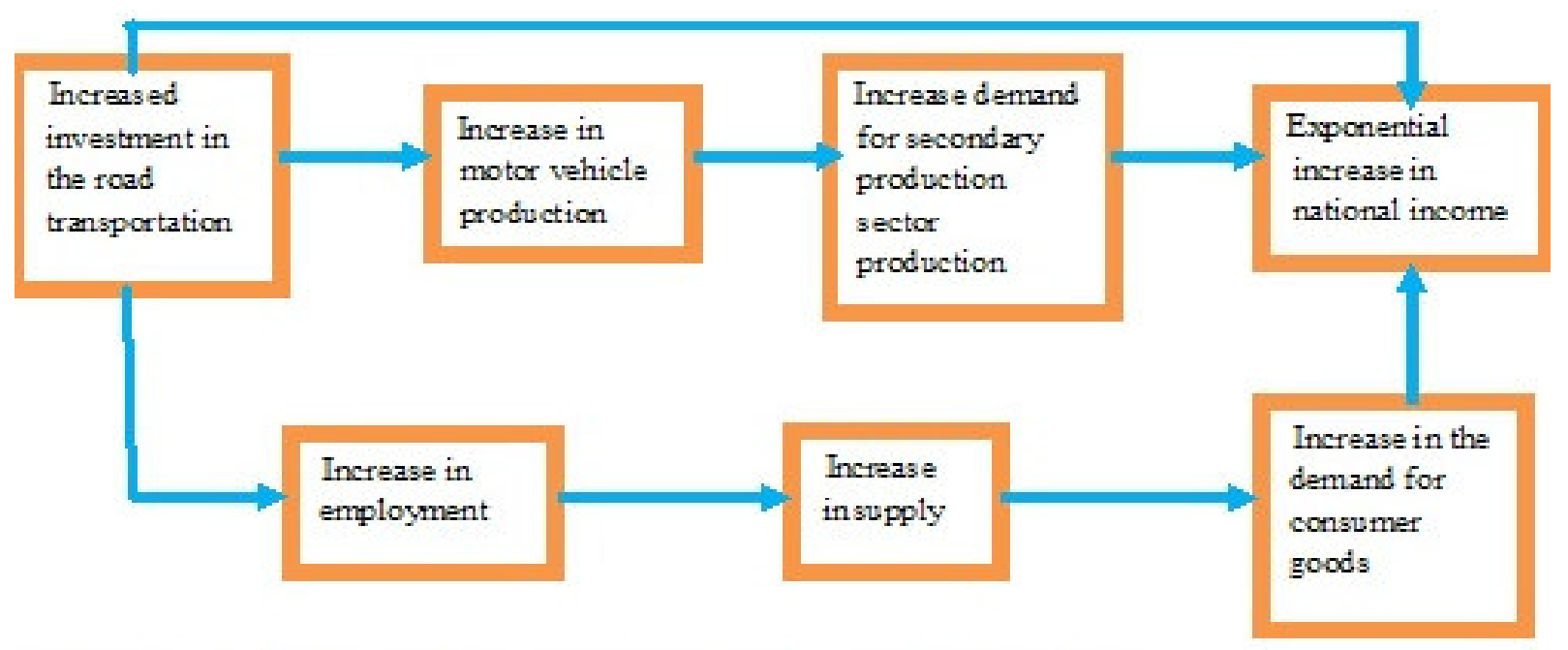

\section{Figure 1. Forward-induced effects of road construction on economic growth}

\subsubsection{Road construction follow-up ripple effects on economic growth}

The road construction has follow-up ripple effects on economic growth is the direct and indirect contributions of road transport infrastructure built on economic development once in operation. The direct contributions include lowering transportation costs, providing door-to-door services, improving accessibility and safety. According to Peng (2012), new infrastructure put into operation is able to alleviate the transport pressure to reduce the crowded road ways, transportation time and transportation costs. New transport modes make the existing transportation network more dense and smooth, thereby increasing the accessibility and safety, resulting to high relative speed of vehicles, and flexibility of route choice.

The indirect contributions of operational road way infrastructure are improved investment environments, optimized industrial structure, accelerated urbanization process and formation of economic traffic belt.

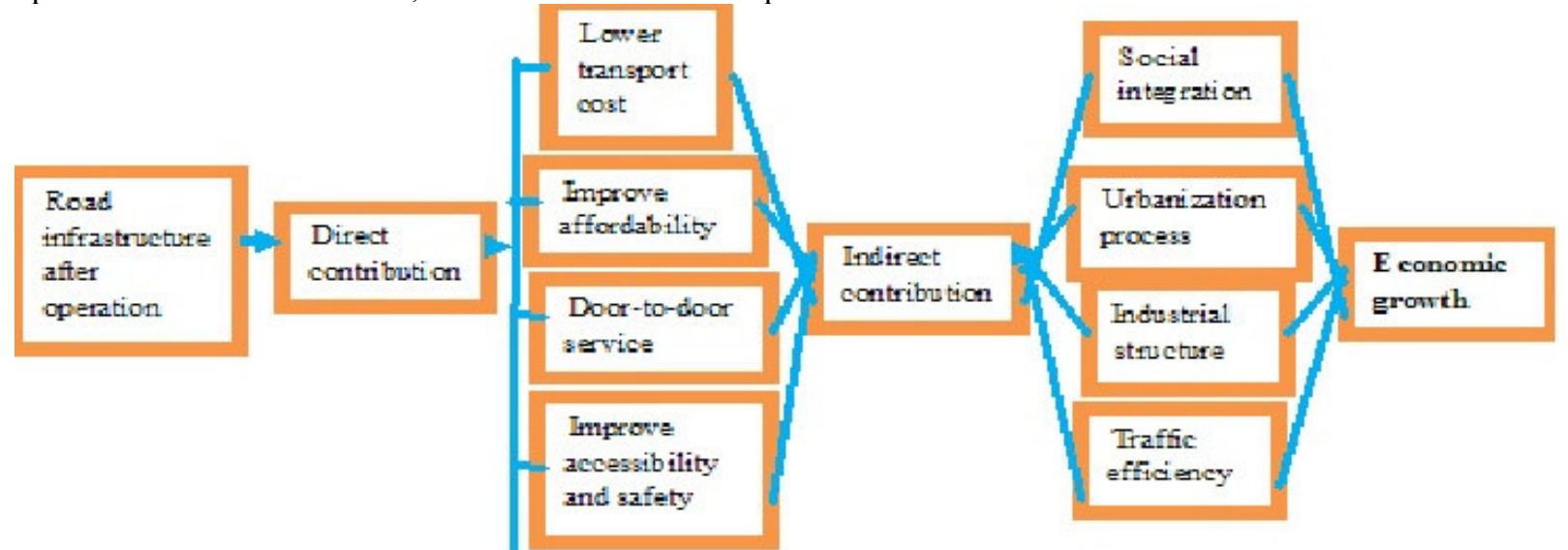

Figure 2. Road construction follow-up ripple effects on economic growth

According to Peng (2012), the role of transportation to promote economic growth is mainly reflected in two aspects as detailed below:

\section{a. Investment multiplier effect and associated industry effect}

Transport infrastructure investment would produce new elements of demand, pulling related industrial development to promote economic growth.

\section{b. Direct economic effect}

After the infrastructure is built and put into operation, it could alleviate the pressure of transport, reduce congestion, save transport time, reduce transportation costs and increase transportation income. Blum (1982), Biehl (1986), and Aschauer (1989) pointed out the level of infrastructure could help explain the productivity growth rate difference between countries. Aschauer (1990) made a comparison between Japan and the United States. Transport infrastructure investment in Japan accounts for $5.1 \%$ of the total investment in the facilities of public investment, resulting in 3.1\% productivity growth per year; while in the United States, only $0.3 \%$ of public facilities investment is used in transport infrastructure with an average annual 0.6\% productivity growth. Emmanuel (1995) indicated the crop yielded $0.26 \%$ more due to the increase in the density of paved roads and rural road network in some 
developing countries.

\section{Theoretical Framework}

\subsection{Theories of economic development}

This section reviews two mainstream theories in economic development, namely, neoclassical growth theory and endogenous growth theory. The implications of these theories for economic development, impact of road transport infrastructure on the industrial structure, the connection of transport to the distribution of productive forces, the strength of transport infrastructure on economic ties, and the importance of transportation on urbanization process were also discussed.

\subsubsection{Neoclassical growth theory}

Neoclassical theory, rooted in neoclassical equilibrium economics, explains growth in terms of the availability and the use of productive factor inputs. The theory was initially developed by Solow (1956) and it argues that development proceeds as firms and households make increasingly more efficient use of their labour, capital and natural resources. Neoclassical theory assumes diminishing returns to investment. It argues that provided there are no major barriers to the operation of market forces, in an integrated national space economy there are strong pressures leading to the general convergence of incomes over time. Disparities are unlikely to be persistent, since such inequalities will set in motion self correcting movements in prices, wages, capital, and labour, which impart a strong tendency toward convergence. Two of the earliest and most influential statements of this view are Borts and Stein's (1964) classic study of development in the United States (US) and Williamson's (1965) analysis of the evolution of income differences in advanced industrial countries.

Over the past decade, empirical work by economists on cross-national and cross-convergence has proliferated. Barro and Martin $(1992 ; 1995)$ on US states, the Japanese prefectures, the European regions and Canada provinces are probably the most cited ones. They tested for absolute convergence of per capita incomes across those regions and found the speed at which regions of different countries converge to their respective national means is about 2 percent per annum. Although it showed evidence of long-term convergence, the slow rate is much less than would be expected from a standard neoclassical view of the growth process (Martin and Sunley, 1998). Moreover, another problem is that they assumed the underlying convergence-generating process is identical across space, when in reality it is likely that the rate of convergence will vary from region to region (Quah, 1993; Canova and Marcet, 1995). Furthermore, the approach fails to take into account how different regions relate to one another, whereas the growth trend of a region may actually depend crucially on the growth trajectories of others (Quah, 1993).

The study by Armstrong (1995) and Quah (1996) demonstrated that spill over effects of labour, capital, technology and other influences on growth are geographically localised. All these cast doubts on the validity of neoclassical growth theory and its assumption of diminishing return to investment is questioned.

\subsubsection{Endogenous growth theory}

There is a progressive dissatisfaction with neoclassical growth theory, this give rise to endogenous growth theory. Instead of assuming factors, in particular technological change and human capital, as exogenous by neoclassical growth theory, endogenous growth theory treats them as endogenous to the growth process (Martin and Sunley, 1998). Endogenous growth theory has its origin in cumulative causation theories linked to Weber (1909), Isard (1956), Myrdal (1957) and Hirschman (1958). There are several main types of endogenous growth theory (Martin and Sunley, 1998). One focuses on the returns to capital investment, another on learning-by-doing and the improvements in knowledge, skills, and human capital that workers accrue as a result of being employed. Another variant is called Schumpeterian and is based on the temporary monopoly rents which companies gain from innovations, which in turn drive the growth process. In all three cases some of the increasing returns gendered in human capital and through innovations may be geographically defined (Sunley, 2000).

According to endogenous growth theory, there are no necessary reasons why growth and incomes should converge, even over the long run (Martin and Sunley, 1998). To the contrary, divergence is more likely. The models of growth advanced by writers such as Perroux (1950), Myrdal (1957), and Kaldor (1970) predict that incomes will tend to diverge, because market forces, if left to their own devices, are spatially dis-equilibrating. Economies of scale and agglomeration lead to the cumulative concentration of capital, labour, and output in certain regions at the expense of others. Development is highly path dependent; temporary conditions and shocks, as well as historical "accidents", may have permanent effects as pattern of specialisation, of economic success or economic backwardness, become "locked in" through external and self reinforcing effects. Various countervailing forces (congestion diseconomies, "trickle-down" effects, and governmental fiscal transfers) may keep divergence in check, but are considered unlikely to be sufficient to promote convergence (Martin and Sunley, 1998).

Economies of agglomeration play an important role in the process of cumulative causation. The advantages of agglomeration are summarised by Amin (2000) as follows.

1. It reduces transaction and transport costs.

2. There are economies deriving from specialisation, both by the locality in a given product, and by its firms in a particular task. 
3. The specialisation of an area is more likely to continuously 'stimulate spin-off and new entrepreneurship.

In their seminal book, Dicken and Lloyd (1990) argued that an important basis of agglomeration economies is the connections or linkages between economic activities within a relatively restricted geographic area. In the final analysis, any firm is but one part of a complex chain of production held together by direct or indirect linkages between a series of firms. Through such linkages, external economies are transmitted to the individual production unit via its network of interconnections with other elements in a system. In addition, other economies may be derived by association. Moreover, complementary or similar industries, by recruiting and training a labour force, for instance, provide a localised cluster of particular labour skills. These skill pools add to the attractiveness of such areas for particular specialised industries (Dicken and Lloyd, 1990). Porter's $(1990,1998)$ study of cluster moves the theory of economies of agglomeration one step forward. According to Porter, cluster is defined as "geographic concentrations of interconnected companies, specialised suppliers, service providers, firms in related industries, and associated institutions (for example, universities, standards agencies and trade associations) in particular fields that compete but also cooperate" (Porter, 1998). Rather than focusing on the need to build industries with linkageto many other industries, Porter (1998) argued what is important is to encourage the development of fields with the strongest linkage to or spill over with each cluster.

\subsection{Implications of economic theories on economic development}

It is important for policy makers to adopt appropriate strategy based on their own circumstances. Neoclassical theory suggests investing on infrastructure and this is the strategy that has been adopted by regions. But it appears that infrastructure investment is only a necessary but not sufficient condition for regions to achieve sustainable economic development.

Endogenous growth theory focuses on increasing returns and positive externalities. The major source of increasing returns comes from economies of agglomeration. The result of the operation of a circular and cumulative process of economic development is that the geographic pattern of development is uneven. Such unevenness is structured in a particular manner into two major components: a dominant core and a subdominant periphery (Dicken and Lloyd, 1990). It is obvious that some economic activities exert a more powerful effect on development in an economic system than others. Therefore, for the development of a periphery region, it is critical to find a growth pole, which consists of a cluster of expanding industries that are spatially concentrated and set off a chain reaction of minor expansions in the surrounding hinterland (Haggett, 1975).

Policy makers should also bear in mind that industrial development is not synonymous with growth (Markusen, 1985). As Sheppard (2000) puts it in the search of increasing competitive advantages firms have more options and powers than regions. Firms can relocate their activities and staff to a new place which suits their strategic purposes, while regions cannot move (Sheppard, 2000). Markusen (1985) also warned that incentives and enticements to firms in the form of free land, tax abatements, or capital subsidies may not be linked to job creation. These types of aid may increase the corporate mobility or accelerate their movement through the profit cycle, with adverse longer-term consequences for the economies. Above all it suggests that aiding firms no longer guarantees aiding workers because boosting the profitability of a company is not necessarily linked to job creation in any particular sector, in any particular location.

Furthermore, regions on the one hand, endeavour to seek the propulsive sectors that could act as growth poles for the region. On the other hand, they need to remain vigilant about the potential harm that oligopolists could cause to the economy in the longer run. To qualify as a propulsive industry or firm, Dicken and Lloyd (1990) argued that there are four requirements.

1. The industry or firm should be relatively large if it is to generate sufficient direct and indirect effects.

2. It should be relatively fast-growing.

3. It should have a high linkage with other industries or firms in order for the effect of its growth to be transmitted.

4. It should be innovative.

Air transport might be an economic sector to fulfil this role. A development based on natural or human-made attractions offers the road transport sector comparative advantages over other economic sectors. As a derived demand and a means to an end, road transport attracts large income from demand outside the region but is still dependent on strong local linkages. Moreover, the sector is largely combined with small, medium, and large sized enterprises with their roots in the local economy. The contributions of other sector are also crucial for the viability of road transport sector. Hence, it has the ability to exert a propulsive force on economic growth.

\subsection{Growth pole and growth centre theory}

In the 1950s, French economist, F. Peoux proposed a growth pole theory with the joint efforts of the French economist JR Boudeville. The concept of the growth pole is extended to the significance of the geospatial city, town or other geographic units such as the first propulsion unit, and underdeveloped areas. The basic content of the growth pole theory are: 
1. The development of one or several of the leading industrial sectors with economic and technological links with other economic production will be driven by the corresponding development of other sectors. That means the development will be often affected by other sectors compared with its own development.

2. The results of the above development for the region are production greater than their own needs.

3. The growth pole extends to all directions in the surrounding area: The "polarization", which is gathering process, is an increase of its very strong economic and technological strength and favourable conditions.

4. Diffusion tends to be the dominant process of the growth pole theory. On one hand, the proliferation of material and energy output and space develops itself, so it grows pole scale, increasing strength; On the other hand, the formation of the new growth pole will promote the progress of diffusion.

Growth axis theory is a direct combination of transport and economic development. Werner Sombart, in the 1960 's, stressed that the construction of transportation routes will guide and promote the role of economic activity. The theory is that connecting the centre of the city's major transportation routes (rail, road) will form a new and favourable location, convenient movement of population, and reduce transportation costs, thereby reducing the cost of production. The new traffic arteries of industrial zones will attract labour, form the favourable investment environment, and gather the corresponding industry, resulting in new industrial zones and residential areas. An axis of transportation as a "spindle" will gradually form an industrial zone, and transportation routes act as the foundation of the formation of the axis of development. Territorial control plans in the Federal Republic of Germany, according to the growth axis theory, improved traffic conditions, adjusting the size of investment and population in one region to guide the construction of industrial zone. In the end, it achieved good results.

\subsection{Road transport infrastructure on the industrial structure}

Industrial structure is the ratio between the primary industry, secondary industry and tertiary industry. Optimization of industrial structure is to achieve a rational allocation of the proportional relationship between the different industries, and to seek the industry to upgrade. Developed road transportation systems may eliminate the geographical limits between the different regions to accelerate the formation of Common Market in the region. The principle of survival of the fittest competition in the market economy can change the mode of economic growth, optimizing the structural relationship of different industries. As a result, the economy would develop to the direction of integration. The higher the degree of the economic integration is, the larger the scale of the industry will be formed, which would further enhance the transport routes to cover an area to promote the development of tertiary industry and high-tech industries (Peng, 2012).

\subsection{Connection of transport infrastructure to the distribution of productive forces}

Improvement of transportation conditions closely connects production with consumption, eliminating the contradiction between supply and demand. The place to produce could be farther away from the place to consume. The agricultural production base is generally located in thesuburbs; more processing plants are gathered in marginal urban areas. If there is no convenient and efficient transportation network to support, the raw materials and products would not be timely delivered to the destination. As a result, the production base of agricultural products and processing plants would not spread to the outskirts of the city (Peng, 2012).

\subsection{The strength of transport infrastructure on economic ties}

An important prerequisite for economic development is the rapid movement of personnel and resources. If the process flow of personnel and resources is restricted, the production, consumption, exchange and distribution of all parts will have been varying affected. Transportation is the basic condition of movement of people and goods, and can promote the flow of resources. The other functions with regard to strengthening of economic ties are:

1. It achieve the optimal allocation of resources in the market competition mechanism,

2. It helps break the restrictions of economic development,

3. It helps to create access to resources in the broader social environment and gain a larger market space for development. A well developed transport networks are good opportunity for industrial scale and upgrading industrial structure (Peng, 2012).

\subsection{The importance of transportation on urbanization process}

Urbanization is the process of socio-economic changes. It includes the scale of the urban population expanding, urban land extending to the suburbs, the number of cities increasing and urban social, economic, technological changes entering the villages in the process. From the definition of urbanization, the process requires a large number of staff and capital flows. The agricultural population converting to non-agricultural population means the agricultural population flows to the cities, while urban land extending to the suburbs shows that the capital injection in suburbs is needed to exploit available land. These processes are inseparable from transportation systems. Without advanced transport networks backing up, the resources between towns and cities centres could not be a 
rational flow, and resources could not be fully utilized, so the process of urbanization would be severely affected (Peng, 2012).

\section{Conclusion and Recommendations}

The following are areas to support the sustainability of road infrastructure projects in Nigeria:

1. Public investment should not be constrained by accounting methods which impede focus on economic returns. In this case, fiscal targets should be useful as a strategic management tool that will incorporate the value of public sector assets rather than concentrating solely on public sector debt. However, there is no distinction between extra borrowing to finance consumption and borrowing to finance investment in new roads or in repairing the condition of existing road infrastructures. The failure to use proper public accounting methods makes public investment such as road maintenance will look artificially expensive and hampers good decision-making. It is like judging a firm solely on the profit and loss account while ignoring the balance sheet (Novella, Miguel, and Jennifer, 2013).

2. Road pricing is an idea whose time has come, and it involves no major technological impediments to a system that would manage congestion, be fairer and improve incentives for building and maintenance. To the extent that there are political impediments with moving to comprehensive road pricing, these can be overcome in the longer term. A new regulator should administer the system following a regulatory asset base model, an approach that has proved to be successful in other areas of infrastructure. By creating dedicated revenue streams, this would help to provide a long-term solution to the problem of road investment, maintenance and finance. Road pricing could be made attractive to the electorate by accompanying its introduction with a cut in fuel duty as a large component of the tax is currently rationalised by the need to limit congestion. In some circumstances, federal roads could be auctioned off and shadow tolls introduced in the section of the road network. Road pricing strategy is potentially a more efficient solution to combating road congestion and could increase the productivity of transport users in terms of time and space utility. It is also a strategy to enforce policy on the articulated vehicles, trucks, and tankers to restrict their movement to a particular time and location, as they are not meant to ply all road networks.

\section{REFERENCES}

Adeniran, A. O. (2016), "Impacts of the Fourth Industrial Revolution on Transportation in the Developing Nations", International Educational Scientific Research Journal, 2(11), 56-60.

Amin, A. (2000), "Industrial Districts" In: Sheppard, E. and Barnes, T. J. Companion to Economic Geography, MA: Blackwell.

Barro, R. J., \& Sala, I., \& Martin, X. (1992), "Regional growth and migration: A US and Japan comparison", Journal of the Japanese and International Economies, December.

Barro, R. J., \& Sala, i., Martin, X. (1995), "Economic Growth", New York: McGraw Hill.

Baumol, W. J., Panzar, J. C., \& Willig, R. D. (1982), "Contestable Markets and the Theory of Industrial Structure”, New York: Harcourt Brace Jovanovich.

Button, K., \& Stough, R. (2000), “Air Transport Networks: Theory and Policy Implications”, Northampton,MA: Edward, Elgar.

Canova, F., \& Marcet, A. (1995), "The Poor Stay Poor: Non-convergence Across Countries and Regions", Discussion Paper 1265, London:Centre for Economic Policy Research.

Crafts, N. (2009), "Transport infrastructure in investment: implications for growth and productivity", Oxford Review of Economic Policy, 25(3): 327-343.

Dicken, P., \& Lloyd, P. (1990), “Location in Space: Theoretical Perspectives in Economic Geography”, NewYork: Harper Collins Publishers.

Hirschman, A. (1958), "The Strategy of Economic Development", New Haven, CT: Yale University Press.

Isard,W. (1956), "Location and Space Economy", Cambridge, MA: MIT Press.

Kaldor, N. (1970), "The case for regional policies", Scottish Journal of Political economy, Nov. 337-348.

Martin, R. \& Sunley, P. (1998), "Slow convergence? The new endogenous growth theory and regional development”, Economic Geography, 74(3), 201- 227.

Myrdal, G. (1957), "Economic Theory and Under-developed Regions", London: Duckworth.

Novella, B., Miguel, C., \& Jennifer, K. (2013), "Infrastructure and growth. Centre for Economic Performance", Economic and Social Research Council, Pp. 1-45

Papacostas, C. S., \& Prevedouros, P. D. (2000), “Transportation Engineering and Planning” (3 ${ }^{\text {rd }}$ Edition). [online]. Prentice Hall.

Perroux, F. (1950), "Economic space: theory and applications", Quarterly Journal of Economics, 64, 89-104.

Porter, M. E. (1998), “On Competition”, A Harvard Business Review Book, Boston: MA: Harvard Business School. 
Quah, D. (1993), "Empirical cross section dynamics in economic growth", European Economic Review, 37,427443.

Quah, D. (1996), “Regional Convergence Clusters Across Europe”, Discussion Paper 1286, London: Centre fore Economic Policy Research.

Rodrigue, J. P., Claude, C., \& Brian, S. (2006), "Geography of Transport Systems", First Published 2006 by Routledge.

Sheppard, E. (2000), “Competition in space and between places”, In: Sheppard, E. and Barnes, T. J. Companion to Economic Geography, MA: Blackwell.

Solow, R., M., (1956), “A Contribution of the Theory of Economic Growth”, Quarterly Journal of Economics, 70, 65-94.

Sunley, P. (2000), “Urban and regional growth", In: Sheppard, E. and Barnes, T. J. Companion to Economic Geography, MA: Blackwell.

Weber, A. (1909), "Theory of the Location of Industries, Chicago",: University of Chicago Press.

Williamson, J. G. (1965), "Regional inequalities and the process of national development", Economic Development and Cultural Change, 13,1-84. 